\title{
E-PLATFORMS FOR UNIVERSITY-BASED ENTREPRENEURIAL ECOSYSTEMS DEVELOPMENT
}

\author{
Marina Slonimska \\ Polotsk State University, Belarus
}

\begin{abstract}
As economic co-ordination becomes increasingly globalized the key interactions among firms in specific industry clusters become regionalized. University-based entrepreneurial ecosystems are believed to be a compromise to foster entrepreneurship and economic development in a regional context. The modern university-based entrepreneurial ecosystems are mainly based on informational flows and e-platforms. However, the process of how the ecosystems come into being, how university-based ecosystems can be nurtured has not been researched enough at present. This article contributes to the field by recommending a framework enabling this process through the development of e-platforms as a regional development model.

The network theory perspective is used as an analytical approach to determine how the mechanism works in the entrepreneurial ecosystem and how it contributes to regional competitive advantage through knowledge transfer and innovation. An in-depth interview method with a semi-structured questionnaire, a literature review, and a statistical analysis are used as research methods. The study context is the Vitebsk region, which is located in the northern part of Belarus.
\end{abstract}

Keywords: e-platforms, regional development, regional innovation system, regional policy, university-based entrepreneurial ecosystem.

\section{Introduction}

The role of entrepreneurs has been recognized to be of great significance in accelerating the pace of growth of economic development of any country. Entrepreneurship is seen as one of the basic skills that individuals need to succeed in a highly competitive and innovative society. One of the impacts that entrepreneurship can have on education is high levels of student motivation and engagement it can trigger, leading to deeper learning (Lackéus, 2015). However, the potential of entrepreneurial education has not been fully realized in Belarus. One of the reasons is the lack of an entrepreneurial ecosystem (EE) which has led to a gap between universities and private businesses.

University teachers, who live in low entrepreneurial culture regions do not have any business experience or stable relationships with local entrepreneurs. 
Accordingly, they have no idea what skills and competencies for entrepreneurship activity are necessary or how to develop tools and techniques for such skills and competencies among undergraduate, graduate, and post-graduate students and how to identify region-specific entrepreneurship opportunities and challenges.

The research problem of the current study is to conceptualize universitybased EE building in a specific territory using the system of e-platforms. Based on the research problem, the current research aims at further developing the theoretical understanding of e-platforms' role in EE functioning and applying the proposed algorithm of EE development using the system of e-platforms in the context of the Vitebsk region (Belarus).

We present a case study of the Vitebsk region (Belarus), which encompasses a number of activities and programs implemented over the past 3 years and connected with entrepreneurial networking. By analyzing these programs we provide some tangible examples as to how different regional actors and eplatforms can be better embedded within regional EE, and how key players in the system such as higher education institutions can assist the development of EEs at the regional level.

The paper is structured as follows. The first section discusses the origins and definitions of the EE concept and related concepts, role of universities and eplatforms in enabling EE concept implementation and models of e-platforms development. The next section presents the results of the research projects in the case of the Vitebsk region (Belarus) to approve the hypothesis about the role of universities and e-platforms in enabling EE concept implementation and to demonstrate the suggested model of e-platforms development.

\section{Literature Review}

A new way of looking at business in biological and ecological terms was offered by James E. Moore in 1993. He adopted the biological concept of an ecosystem to business development theory. He used the term 'ecosystem' as a biological counterpart and suggested that 'a company be viewed not as a member of a single industry but as a part of a business ecosystem that crosses a variety of industries', and 'gradually moves from a random collection of elements to a more structured community' (Moore, 1993, p.76). As Edward J. Malecki shows, the entrepreneurial ecosystem concept has become dominant since 2016, alternative concepts, such as a system of entrepreneurship and infrastructure for entrepreneurship, continue to be used but remain less prevalent (Malecki, 2018).

The entrepreneurial ecosystem approach bridges the innovation system approach and entrepreneurship studies (O’Connor at el., 2018). It relates to such concepts as industrial clusters, industrial districts, learning regions, and the triple 
helix model of industry, government, and university interactions (Stam, 2015). All such systems have the following characteristics: a collection of elements; interactions between the elements; and a purpose or function. Daniel Isenberg names the entrepreneurial ecosystems approach as a 'pre-condition' for the successful development of cluster strategies, innovation systems, knowledge economy or national competitiveness policies (Isenberg, 2011).

Industrial clusters 'refer to the tight connections that bind certain firms and industries together in various aspects of common behavior, e.g., geographic location, sources of innovation, shared suppliers and factors of production, and so forth' (Bergman, Edward, 2020, p.2). Industrial districts are one type of a cluster, which are characterized by groups of co-located small- and medium-sized companies operating in light manufacturing sectors of the economy (Porter \& Ketels, 2009). Marta Götz and Barbara Jankowska showed that the mechanisms and functionalities provided by clusters well aligned with the features of Industry 4.0, industrial Internet and the integrated industry. And, as they concluded, implementation of the concept of Industry 4.0 is transforming clusters into 'territorially unlimited and neutral to the location of the cooperation platform' (Götz \& Jankowska, 2018, p.388).

A large subset of research focuses on universities as the central actors or hubs of EE (Malecki, 2018). EEs usually come out in locations with place-specific assets, and universities are among such assets (Carvahlo, 2017). As the case of Lahti region (Finland) showed, the knowledge, innovation and entrepreneurship ecosystem in the region is an effective environment for practice-based innovation formed by universities and other research units (Harmaakorpi, 2020). The most changed part of the innovation environment is the structural development of the university system, which enables better use of research knowledge for the platforms and start-ups in the region (Harmaakorpi, 2020).

There are several models of entrepreneurial ecosystems. Daniel Isenberg identifies six domains within the system: a conducive culture, enabling policies and leadership, availability of appropriate finance, quality human capital, venture friendly markets for products, and a range of institutional supports (Isenberg, 2011, 13). Johannes Ulrich Bramann added a seventh condition - ICT infrastructure (Bramann, 2017). World Economic Forum lists eight following pillars of an entrepreneurial ecosystem. Additional ecosystem elements are education \& training; and major universities as catalysts (World Economic Forum, 2014). Thus, the entrepreneurial ecosystem model most fully can be represented from eight elements (pillars), listed by World Economic Forum, and the ninth element (condition) - ICT infrastructure.

The network theory perspective is employed as an analytical approach to determine the working of the mechanism within an entrepreneurial ecosystem that 
subsequently affects a region's competitiveness (Purbasari, Wijaya, \& Rahayu, 2018). The main network effects are improving companies' competitiveness in inter-firm networks and growth in business performance with increasing network size. The main condition for network effects is trust among network members and strong information technology support to collaborate successfully (MiczyńskaKowalska \& Slonimska, 2020).

Platforms promote users' and customers' participation in the innovation process and reshape business functions and operations. Digital platforms (eplatforms, ICT-based platforms) are becoming a prominent technological and business model for collaborative innovation (De Falco, Renzi, Orlando, \& Cucari, 2017). E-platforms are an organizational form made up of a technological architecture and governance mechanisms for managing autonomous complementors (Saadatmand, Lindgren, \& Schultze, 2019).

According to Paolo Spagnoletti, Andrea Resca \& Gwanhoo Lee, digital platforms should support three types of social interaction: information sharing, collaboration, and collective action (Spagnoletti, Resca, \& Lee, 2015). Such a concept is adaptable for EEs development. First, it is necessary to create eplatform resource available to all, and allow free participation. It can stimulate different potential actors of the entrepreneur ecosystem in a region to communicate and build trust. Then actors can follow rules and engage in collaborative open innovation activities that require substantial group coordination. At the third stage, digital platforms can support collective actioncentered online communities. They should engage trusted members of small and tightly coupled communities in the exchange of information and provide coordination mechanisms.

Interorganizational systems (IOSs) are information and communication technology-based systems that transcend legal enterprise boundaries (Kumar \& Dissel, 1996). Kuldeep Kumar \& Han G. van Dissel suggest a three-part typology for lOSs: pooled information resource lOSs; networked lOSs; and value/supplychain lOSs in correspondence with the three types of interorganizational interdependence.

The first type, pooled information resource lOSs, is an inter-organizational sharing of common IT resources. Typical IT resources shared in a pooled fashion include common databases, common communication networks, and common applications (Kumar, \& Dissel, 1996). At the initial stage of EEs development, it is generally necessary to have shared access to information to organise cooperation between its participants and form a project portfolio. To implement such tasks, it is enough to create a cluster website, for example.

The second type, networked lOSs, operationalize and implement reciprocal interdependencies between organizations. They typically represent joint ventures between various partners, each partner providing a different specific advantage. 
They could involve using desk-top/screen-sharing technologies, CAD/CASE data interchange and repositories, discussion databases, synchronous and asynchronous time/place computer-based systems for supporting collaborative work, and the integration of these technologies with video-conferencing (Kumar, \& Dissel, 1996). After the problem of trust-building among different EEs actors is solved, there is an opportunity to organize joint innovation projects for this, it is necessary to organize open innovation platforms. After the problem of trust-building among different EEs actors is solved, there is an opportunity to organize joint innovation projects based on open innovation platforms. Living Labs (LLs) are an effective type of open innovation platforms. LLs are defined as user-centred, open innovation ecosystems based on systematic user co-creation approach, integrating research and innovation processes in real-life communities and settings (European Network of Living Labs, 2021).

The third type of IOS, value/supply-chain IOS, supports customer-supplier relationships and occurs as a consequence of these relationships along the value/supply chain. The primary motives behind these collaborations are the reduction of uncertainties in the supply chain, thereby gaining cost, cycle time, and quality advantages over competing supply chains in the industry (Kumar \& Dissel, 1996).

As the number of cluster members increases due to the inclusion of small businesses that produce and sell final products, the relevance of the formation of integrated supply chains and the need for the development of a MIS supply chain is growing.

Thus on the literature review results, it may be concluded that e-platforms and IOSs play an important role in entrepreneurial ecosystems development. Universities are the most active actors of entrepreneurial ecosystems, and they can contribute a lot to e-platforms / IOSs development. To facilitate entrepreneurial ecosystems improvement, a model of e-platforms / IOSs development is proposed, that is shown in figure 1.

The hypothesis about universities and e-platforms' role in EEs development has been analyzed in 2018-2020 while carrying out two research projects in the Vitebsk Region (Belarus). Both studies were conducted with the participation of the author.

The first study was carried out in 2018-2019 as a part of the international technical assistance project "Development of the October Economic Forum", registered in the database of international technical assistance projects and programs of the Ministry of Economy of the Republic of Belarus on July 20, 2016, under No 2/16/000810. The project goal was to increase Belarusian nongovernmental organizations' (NGOs') potential in promoting responsible economic policies at local and national levels. Some questions were included in 
the questionnaire about the role of networking and business-cooperation in SME activity (Slonimska, Yasheva, \& Dubko, 2019).

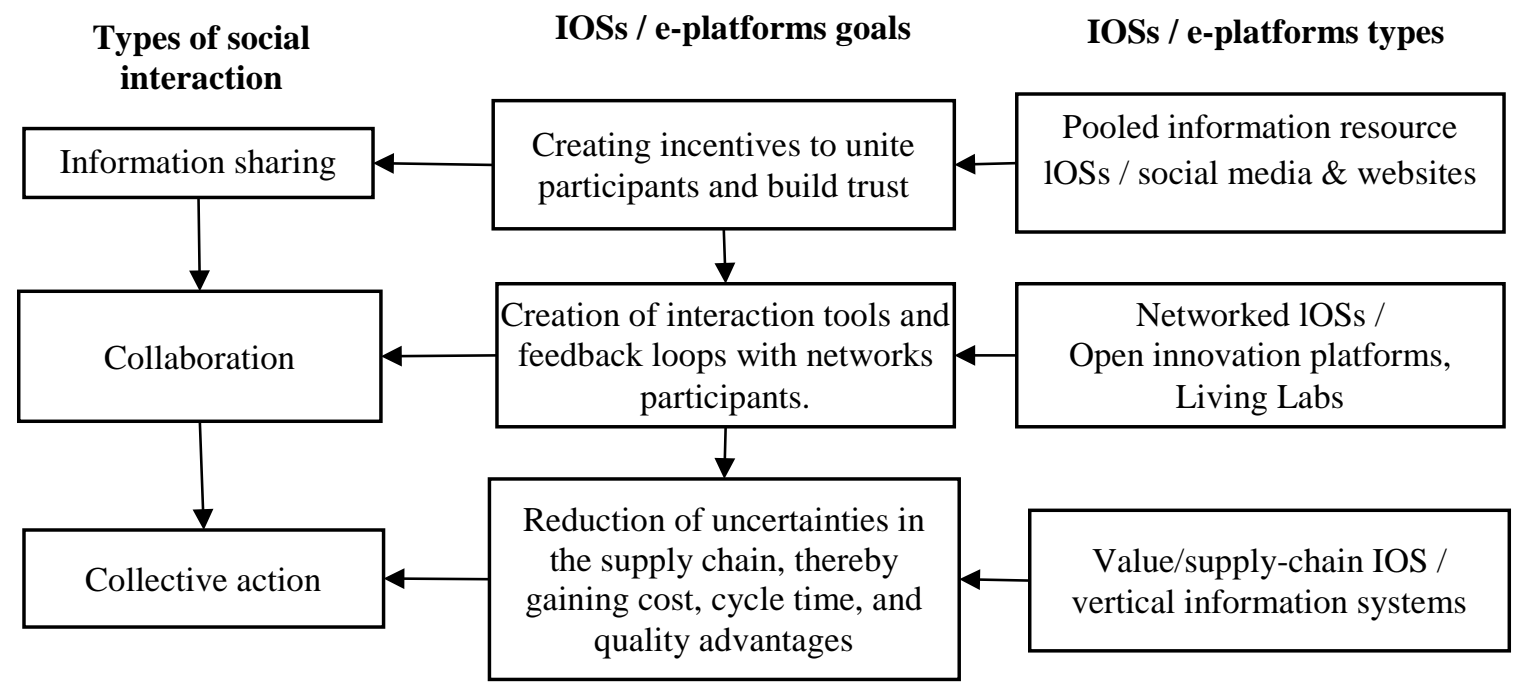

Figure 1 A Model of E-platforms / IOSs Development (created by the author)

The second study was carried out in 2019 as a part of the research on the topic 'Scientific substantiation of sustainable development of JSC 'Naftan' within the Novopolotsk Innovative and Industrial Petrochemical Cluster'. One of the goals of the project was to develop the e-platform concept for the Novopolotsk Innovative and Industrial Petrochemical Cluster (NIIPC).

\section{Methodology}

The SME leaders survey was conducted using in-depth interviews (21 respondents) and the method of a structured questionnaire survey (400 respondents). The indicated sample size allowed us to obtain results with a reliability of $95 \%$ and an accuracy of no less than $\pm 5 \%$.

The selection of respondents for a structured questionnaire was carried out by random sampling from the list of enterprises located in the national business directory on goods and services "Business Belarus 2018", stratified by the number of SMEs in districts and cities of the Vitebsk region. The planned sample structure was partially changed due to the refusal of individual respondents to participate in the survey.

The in-depth interviews were conducted in July-August 2018, whereas the questionnaire survey was conducted in February-August 2019. Respondents interviewed by in-depth interviews were leaders of SMEs located in six settlements of the Vitebsk region. 


\section{Research Results}

A survey of entrepreneurs in the Vitebsk region made it possible to assess the level of interaction between entrepreneurs themselves and to assess their willingness to cooperate with local government bodies, universities, and other regional stakeholders to estimate the EE development perspective.

According to the survey results, about $20 \%$ of the respondents do not consider it useful to cooperate with other enterprises to develop their own businesses. About half of the respondents believe that they need cooperation with partners, and they need to develop various forms of cooperation. However, the survey did not identify any formal networks of SMEs in the region.

The attitude of entrepreneurs towards unions and associations, as shown by the survey, varies significantly. All the surveyed members of the Association of Employers and Entrepreneurs of the Vitebsk region consider membership in the organization beneficial for their business development. Most of nonmembers showed negative attitude to membership in associations and unions of entrepreneurs.

It should be noted that none of the respondents were aware of entrepreneurship development councils created by the local government. It allows us to conclude that the regional business is poorly informed about the local government activities and that there is a low level of trust to these official structures. However, the revitalization of these structures and their transformation into a full-fledged dialogue platform with the expansion of business representatives' powers can be an important tool for developing a dialogue between entrepreneurs and local authorities to solve some local problems or to address them to a higher authority.

According to the respondents, the problems hindering the development of SME cooperation in the Vitebsk region are lack of information about potential partners (noted by 76.8\% respondents), low level of trust between entrepreneurs (76\%), and lack of infrastructure and services for the support of business community cooperation (61\%).

A questionnaire survey of entrepreneurs of the Vitebsk region showed that most of them agree with the need to create e-platforms for communication between entrepreneurs themselves and for communication of entrepreneurs with representatives of local authorities (62.3\% and $62.9 \%$, respectively).

Thus, the study confirms our hypothesis that, at the first stage of the EE idea advancement, it is necessary to develop e-platforms in the region that allow obtaining information about potential partners, forming interest groups, and building trust in the process of communication. 
As a result of public comment, it has been proposed to implement an eplatform in the form of a public-private partnership platform (PPP-platform). It is assumed that a PPP-platform would operate as a space for engaging stakeholders and identifying partnerships. Every regional business must be registered and represented on the platform. This would resolve the issue of lack of information about potential partners. Communication between SME managers on the platform and discussion of common issues would enable the building of trust. It is suggested that SME managers will have an opportunity to communicate with representatives of regional authorities and other stakeholders on how to improve the business environment and how to develop the regional economy focusing on new ideas (Miczyńska-Kowalska \& Slonimska, 2020, p.56).

At the same time, it is proposed to develop university-based e-platforms for every regional cluster. The concept of the e-platform on the base of Polotsk State University was developed with the participation of the author as a part of the research on the topic 'Scientific substantiation of sustainable development of JSC' Naftan' within the NIIPC'. The e-platform development plan includes three stages: 1) the development and implementation of the NIIPC association' website for information resources sharing, including common databases, common communication networks and common applications (IOS pool); 2) development of a horizontal network for organizing innovation activities based on the concept of open innovation (network IOS); 3) development of integrated supply chains along the value chain (OIS supply chain). The second stage of the development of the network interaction platform will be implemented after the increase in the number of members of the NIIPC association, the formation of a portfolio of projects and an increase in site traffic indicators. The third stage will be implemented after SMEs, which produce and sell final products, joined the cluster.

The e-platform as NIIPC website (https://ipnnk.by/) was created in 2020. The project was funded by the Ministry of Foreign Affairs of the Republic of Poland under the Polish Development Cooperation Program. The additional functional blocks of the e-platform according to the e-platform development plan will be added during the cluster project development.

Table 1 summarizes NIIPC stakeholders needs and represents the related e-platform functions. 
Table 1 Interests and Needs of ICNIC Stakeholders and Related E-platform Functions (created by the author)

\begin{tabular}{|c|c|c|}
\hline Stakeholders & Interests and needs & Functional blocks of the e-platform \\
\hline \multirow{3}{*}{$\begin{array}{l}\text { The governing } \\
\text { body of the } \\
\text { Association }\end{array}$} & $\begin{array}{l}\text { Dissemination of information } \\
\text { about ICNIC activities }\end{array}$ & News \& Articles \\
\hline & $\begin{array}{l}\text { Organization of cooperation and } \\
\text { coordination of activities of } \\
\text { Association members, } \\
\text { providing them with } \\
\text { information, methodological, } \\
\text { organizational, consulting and } \\
\text { other assistance }\end{array}$ & $\begin{array}{l}\text { Registration of participants with } \\
\text { different statuses } \\
\text { Q\&A }\end{array}$ \\
\hline & $\begin{array}{l}\text { Projects organization in the } \\
\text { interests of ICNIC }\end{array}$ & $\begin{array}{l}\text { Holding a competition to form a } \\
\text { consortium for the implementation of } \\
\text { approved projects }\end{array}$ \\
\hline $\begin{array}{l}\text { Association } \\
\text { members }\end{array}$ & $\begin{array}{l}\text { Problem solving, development } \\
\text { and implementation of new } \\
\text { processes, goods and services }\end{array}$ & $\begin{array}{l}\text { Database for formulation of problems } \\
\text { to be solved }\end{array}$ \\
\hline $\begin{array}{l}\mathrm{R} \& \mathrm{D} \\
\text { organizations }\end{array}$ & $\begin{array}{l}\text { Receiving orders for research } \\
\text { and development }\end{array}$ & $\begin{array}{l}\text { Placing an application for } \\
\text { participation in a project related to } \\
\text { solving a specific problem } \\
\text { Forum for registered members } \\
\text { Database of innovative projects with } \\
\text { information about their status }\end{array}$ \\
\hline R\&D investors & $\begin{array}{l}\text { Making a profit as a result of } \\
\text { financing innovative projects }\end{array}$ & $\begin{array}{l}\text { Database of innovative projects with } \\
\text { information about their status }\end{array}$ \\
\hline
\end{tabular}

\section{Conclusions and Discussion}

It is assumed that the PPP-platform and university-based e-platforms of regional clusters will interact in the future, implementing joint projects based on the concept of open innovation and will contribute to the formation of an EE in the Vitebsk region. Projects in the field of implementation of Industry 4.0 and Chemistry 4.0 concepts can be the most productive.

Development of cooperation projects in the region of the petrochemical cluster and clusters of other industries, for which the petrochemical industry supplies raw materials (pharmaceutical cluster, light industry cluster, packaging for food cluster) may become a good prospect for SMEs development.

However, there are social and economic risks that can be a hurdle the implementation of a favorable scenario for the EE development in the Vitebsk region. 


\section{References}

Bergman, E. M., \& Feser, E.J. (2020). Industrial and Regional Clusters: Concepts and Comparative Applications. Web Book of Regional Science. West Virginia University. Retrieved from https://researchrepository.wvu.edu/rri-web-book/5

Bramann, J. U. (2017). Building ICT Entrepreneurship Ecosystems in Resource-Scarce Contexts: Learnings from Kenya's “Silicon Savannah”, In: B. Ndemo, T. Weiss (Ed.), Digital Kenya. An Entrepreneurial Revolution in the Making, 227-258. London: Springer Nature.

Carvalho, L. C. (2017). Entrepreneurial Ecosystems: Lisbon as a Smart Start-Up City, In: L.C. Carvalho (Ed.), Handbook of Research on Entrepreneurial Development and Innovation Within Smart Cities (1-19). Hershey: IGI Global. DOI: 10.4018/978-1-5225-1978-2

De Falco, S. E., Renzi, A., Orlando, B., \& Cucari N. (2017). Open collaborative innovation and digital platforms. Production Planning \& Control, 28(16), 1344-1353. DOI: 10.1080/09537287.2017.1375143

European Network of Living Labs. (2021). Retrieved from https://enoll.org/about-us/

Götz, M., \& Jankowska, M. (2018). On the role of clusters in fostering the Industry 4.0. International Business in the Information and Digital Age, 02 Nov, 379-390. DOI: 10.1108/S1745-886220180000013016

Harmaakorpi, V., \& Rinkinen S. (2020). Regional development platforms as incubators of business ecosystems. Case study: The Lahti urban region, Finland. Growth and Change, $51,626-645$.

Isenberg, D. (2011). The Entrepreneurship Ecosystem Strategy as a New Paradigm for Economic Policy: Principles for Cultivating Entrepreneurship. The Babson Entrepreneurship Ecosystem Project, Babson College, Babson Park, MA, 1-38. Retrieved from http://www.innovationamerica.us/images/stories/2011/Theentrepreneurship-ecosystem-strategy-for-economic-growth-policy-20110620183915.pdf

Kumar, K., \& van Dissel, H. G. (1996). Sustainable collaboration: Managing conflict and cooperation in interorganisational systems. MIS Quarterly, 20(3), 279-300.

Lackéus, M. (2015). Entrepreneurship in education. What, why, how. Paris: OECD Publishing.

Malecki, E. L. (2018). Entrepreneurship and entrepreneurial ecosystems. John Wiley \& Sons Ltd. DOI: 10.1111/gec3.12359

Miczyńska-Kowalska, M., \& Slonimska M. (2020). Network mechanisms for supporting entrepreneurially weak regions. Nierówności Społeczne a Wzrost Gospodarczy, 62(2), 47-61.

Moore, J. F. (1993). Predators and Prey: A New Ecology of Competition. Harvard business review, May-June, 75-86.

O’Connor, A., Stam, E., Sussan, F., \& Audretsch D. (2018). Entrepreneurial Ecosystems: The Foundations of Placebased Renewal. In: O'Connor, A., Stam, E., Sussan, F., Audretsch, D.B. (Eds), Entrepreneurial Ecosystems. Place-Based Transformations and Transitions (1-22). New York: Springer.

Porter, M. E. \& Ketels, C. H. M. (2009). Clusters and industrial districts: Common roots, different perspectives. In: Porter M.E. (Eds), A Handbook of Industrial Districts. Edward Elgar Publishing, 172-183.

Purbasari, R., Wijaya Ch., \& Rahayu R. (2018). The impact of the entrepreneurial ecosystem on regional competitive advantage: A network theory perspective. Russian Journal of Agricultural and Socio-Economic Sciences, 11(83), 49-63. 
Saadatmand, F., Lindgren R., \& Schultze U. (2019). Configurations of platform organizations: Implications for complementor engagement. Research Policy, 48, 1-17.

Spagnoletti, P., Resca, A., \& Lee G. (2015). A design theory for digital platforms supporting online communities: a multiple case study. Journal of Information Technology, Feb., 1-17.

Slonimska, M., Yasheva, G., \& Dubko, N. (2019). Predprinimatel'stvo Vitebskoj oblasti: problemy $i$ perspektivy razvitiâ. Vitebsk: OO "Associaciâ nanimatelej i predprinimatelej”. Retrieved from kef.by/publications/research/ konkurentosposobnostregionov-belarusi/predprini-matelstvo-vitebskoy-oblasti-problemy-i-perspektivyrazvitiya.

Stam, E. (2015). Entrepreneurial Ecosystems and Regional Policy: A Sympathetic Critique. European Planning Studies, 23 (9), 1759-1769. DOI: 10.1080/09654313.2015.1061484

World Economic Forum. (2014). Entrepreneurial Ecosystems Around the Globe and EarlyStage Company Growth Dynamics - the Entrepreneur's Perspective, Geneva: Published by World Economic Forum. Retrieved from https://reports.weforum.org/entrepreneurialecosystems-around-the-globe-and-early-stage-company-growth-dynamics/ 